\title{
A Rare Case of Strongyloides Hyperinfection from Hypogammaglobulinemia
}

\author{
Paidi Ramakrishna Reddy, Sujith M. Thomas, A. Rajalakshmi', Deepak Vijayan, Muraleedharan Raman \\ Department of Critical Care, Kerala Institute of Medical Sciences, 'Department of Internal Medicine, Division of Infectious Disease, Kerala Institute of Medical \\ Sciences, Thiruvananthapuram, Kerala, India
}

\section{Abstract}

Strongyloides infection can range from asymptomatic eosinophilia to disseminated disease. Common in tropical and subtropical nations, it can lead to hyperinfection, an autoinfection increasing parasitic burden in immunocompromised. Cell-mediated immunity is important in combating parasite infection. We present a case of Strongyloides hyperinfection in hypogammaglobulinemia which was refractory to conventional treatment but responded to immunoglobulin administration with complete resolution indicating role of humoral immunity also.

Keywords: Agammaglobulinemia, autoinfection, cell-mediated immunity, humoral immunity, parasites, Strongyloides

\section{INTRODUCTION}

Strongyloides, a nematode infection in humans occur when its larval form in soil penetrates skin of human. Remains asymptomatic in immunocompetent persons making diagnosis difficult. Immunosuppression due to low immunoglobulin (Ig) levels causes disseminated infection suggesting the role of humoral immunity in combating Strongyloides infection.

\section{Case Report}

A 57-year-old male patient was admitted with 1 and $1 / 2$ months diarrhea, weight loss, intermittent fever, right loin pain, intermittent abdominal pain, and small volume diarrhea of 3-4 episodes/day for 7-8 months with weight loss of $8 \mathrm{~kg}$ over 8 months. No prior comorbidities. He denied fever, vomiting, cough, urinary symptoms. Recurrent infections, history of tuberculosis, or tuberculosis contact. History not suggestive of exposure to cattle or pets and reported consumption of cooked food mostly and reported no food intolerance. He lives in rural South India and use to walk bare footed in his farm, consume alcohol daily, denied intravenous (IV) drug abuse, or high-risk sexual behavior. He was not on steroids or immunosuppressive drugs. Married, blessed with two children and his other family members were reported healthy. He is bank manager.

\begin{tabular}{|l|l|}
\hline \multicolumn{3}{|c|}{ Access this article online } \\
\hline Quick Response Code: & Website: \\
\hline & www.ijccm.org \\
\cline { 2 - 2 } & \\
\hline
\end{tabular}

A clinical examination remarkable for cachexia, hypotension with a blood pressure (BP) of 80/60, dry tongue, sunken eyes oral candida, and perioral vitiligo. He had generalized macular erythematous, purpuric lesion over trunk and abdomen, which are nonmigratory. Abdominal examination revealed right loin tenderness, bilateral wheezes. There was no neck stiffness and cardiac examination was normal. A provisional diagnosis of chronic diarrhea syndrome with possible sepsis was considered, admitted to medical Intensive Care Unit and started on ertapenem, flucanozole to cover for Gram-negative sepsis of probable gut origin, and oral/esophageal candidiasis. He had neutrophilic leucocytosis, his other significant laboratory parameters were low protein and albumin $(4.8 / 2.2 \mathrm{~g} / \mathrm{dl})$, macrocytic anemia, low mg, K, B12, and folate. His cortisol was normal. Stool sent for gastrointestinal (GI) pathogen multiplex polymerase chain reaction (PCR) panel did not reveal any pathogens (FilmArray, bio'Merieux).

After stabilization of his BP, underwent contrast computed tomography (CT) of the chest and abdomen which revealed

Address for correspondence: Dr. Paidi Ramakrishna Reddy, Department of Critical Care, Kerala Institute of Medical Sciences, P.0. Box: 1, Anayara, Thiruvananthapuram - 695 029, Kerala, India. E-mail: raamrocks24.7@gmail.com

This is an open access article distributed under the terms of the Creative Commons Attribution-NonCommercial-ShareAlike 3.0 License, which allows others to remix, tweak, and build upon the work non-commercially, as long as the author is credited and the new creations are licensed under the identical terms.

For reprints contact: reprints@medknow.com

How to cite this article: Reddy PR, Thomas SM, Rajalakshmi A, Vijayan D, Raman M. A rare case of Strongyloides hyperinfection from hypogammaglobulinemia. Indian J Crit Care Med 2017;21:466-8. 
ground glass opacities in lung and ileocaecal thickening, followed by upper GI endoscopy and biopsy. Revealed antral gastritis. He further underwent colonoscopy and biopsy. Colonoscopy revealed small ulcers throughout colon. His blood sent on the day of admission grew Klebsiella pneumoniae, the extended-spectrum beta-lactamases producer. Stool routine initial sample revealed only pinworms. Biopsy of the duodenal mucosa revealed Strongyloides larval forms [Figure 1]. Colonic biopsy revealed only chronic colitis, did not reveal granuloma or Strongyloides. Repeat stool for Strongyloides was positive for adult worms.

A diagnosis of Strongyloides hyperinfection was considered and he was started on ivermectin orally, his diarrhea settled but a day later developed encephalopathy and was switched to meropenem in meningitic dose. Bran imaging was normal. Cerebral spinal fluid (CSF) done was suggestive of pyogenic meningitis with a cell count of 1200 , protein-213, sugar-40, no organisms on Gram stain. CSF multiplex PCR revealed Klebsiella. A day later CSF culture grew Enterococcus faecium which was resistant to penicillin and sensitive to vancomycin. He improved with meropenem and vancomycin. As repeat stool routine revealed persistent Strongyloides worms, albendazole $400 \mathrm{mg}$ twice daily was added. He also had skin lesions suggestive of larva migrans [Figure 2].

His autoimmune workup was negative. Meanwhile underwent workup for immunosuppression. HIV 1 and 2 antibody was negative, CD4 was 1270. Igs level revealed low IgG, IgM, and $\operatorname{IgE}$ and a normal $\operatorname{IgA}$ levels. There was no evidence of thymoma or no lymph node enlargements to suggest lymphoma in imaging. Peripheral smear did not reveal abnormal cells. Common variable immunodeficiency was considered though it is unusual to present in this age without secondary causes and recurrent bacterial infections. Human T-cell lymphotrophic virus (HTLV) serology, CD19 and CD20, antiendomysial antibody, and tissue transglutaminase antibody results are negative. In view of persistent Strongyloides, in repeat stool examination, and low Ig level he was given a single dose of

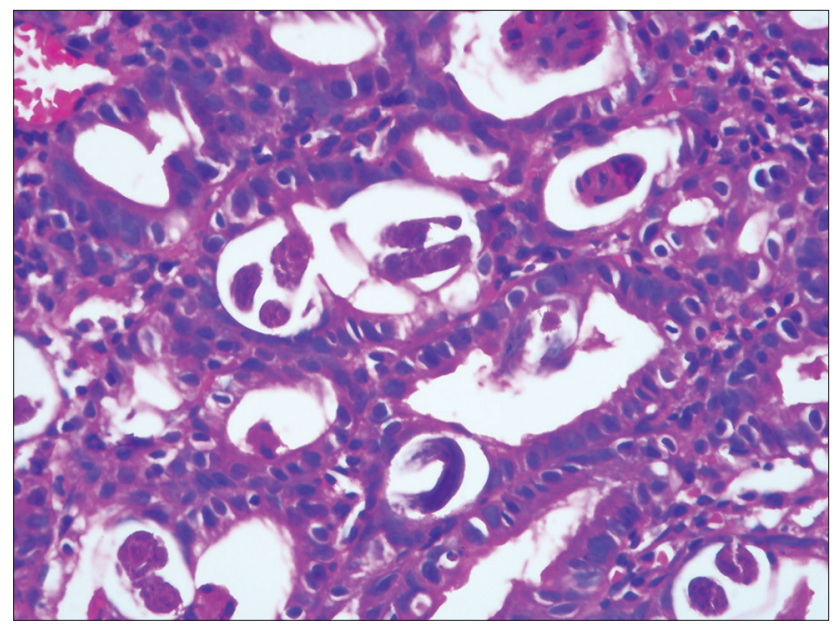

Figure 1: Photomicrograph of duodenal mucosa demonstrating larval form of Strongyloides stercoralis
$400 \mathrm{mg} / \mathrm{kg}$ of IVIg. Although low Ig in his case may be due to low globulins per se still it helped him clear the stool of Strongyloides. He improved remarkably.

\section{Discussion}

Strongyloides infection can have variable presentation ranging from asymptomatic eosinophilia in immunocompetent host to disseminated disease with sepsis. It can also present as acute exacerbation of $\mathrm{COPD}^{[1]}$ inflammatory bowel disease. ${ }^{[2]}$

Strongyloidiasis is endemic in rural areas of tropical and subtropical regions. In India, it is common in southern states. The infection begins when filariform larvae found in soil contaminated with feces comes in contact with human skin. Unlike other helminthic parasites Strongyloides can complete its life cycle entirely within human host. Autoinfection begins when rhabditiform larvae matures into filariform larvae within GI tract. This larval transformation can be accelerated by steroid use and conditions with decreased bowel motility. An intact immune response limits autoinfection, especially cell-mediated immunity plays an important role in combating infection. Under conditions of immunocompromise, this autoinfective cycle can become amplified to cause hyperinfection syndrome. ${ }^{[3]}$ Glucocorticoid therapy is most commonly associated with triggering hyperinfection. ${ }^{[3]}$

Antibodies, complement, and granulocytes have role in protection against Strongyloides larvae. Refractory to treatment can be seen in hypogammaglobulinemia, ${ }^{[4]}$ HTLV infection. ${ }^{[5,6]}$ In our case, HTLV, HIV 1,2 workup is negative. Serum Igs showed low IgG, IgA, and IgE. Such low Igs can be seen in primary hypogammaglobulinemia or secondary to medications, nephrotic syndrome, protein losing enteropathy, intestinal lymphangiectasia, and B-cell malignancy. ${ }^{[7]}$ Role of humoral immunity in Strongyloides infection in suggested by more severe course of strongyloidiasis in hypogammagobulinemia. ${ }^{[4,8,9]}$ Lack of adequate Igs leading to treatment resistance with ivermectin has been shown in these studies. Although IgG is specific for Strongyloides, isolated IgA deficiency leading to Strongyloides infection has been

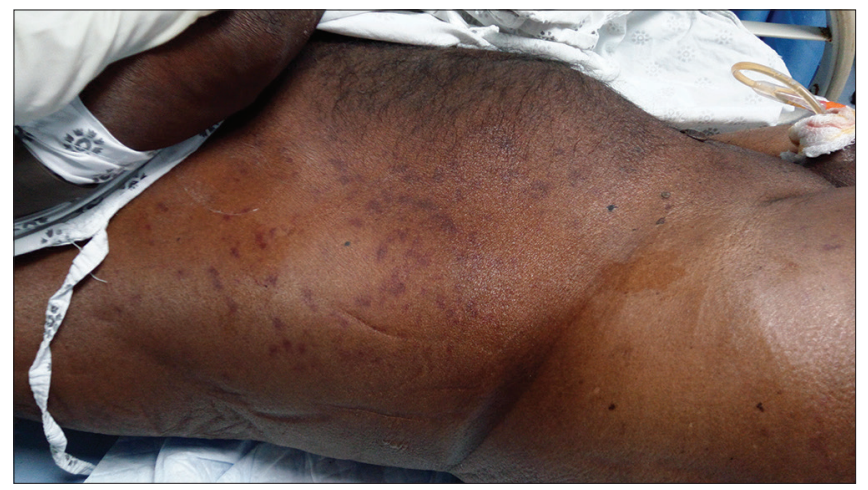

Figure 2: Skin over lateral aspect of abdomen showing lesions of larva migrans 
shown in human and animals, ${ }^{[10]}$ which shows the importance of Igs in immune responses against Strongyloides infection.

\section{Conclusion}

An intact immune response of both cell-mediated and humoral immunity is necessary to limit the dissemination of Strongyloides infection and also for eradication of Strongyloides infestation.

\section{Financial support and sponsorship}

Nil.

\section{Conflicts of interest}

There are no conflicts of interest.

\section{References}

1. Pradhan G, Behera P, Panigrahi MK, Bhuniya S, Mohapatra PR, Turuk J, et al. Pulmonary strongyloidiasis masquerading as exacerbation of chronic obstructive pulmonary disease. Tuberc Respir Dis (Seoul)
2016;79:307-11.

2. Qu Z, Kundu UR, Abadeer RA, Wanger A. Strongyloides colitis is a lethal mimic of ulcerative colitis: The key morphologic differential diagnosis. Hum Pathol 2009;40:572-7.

3. Keiser PB, Nutman TB. Strongyloides stercoralis in the immunocompromised population. Clin Microbiol Rev 2004;17:208-17.

4. Ashraf M, Gue CL, Baddour LM. Case report: Strongyloidiasis refractory to treatment with ivermectin. Am J Med Sci 1996;311:178-9.

5. Terashima A, Alvarez H, Tello R, Infante R, Freedman DO, Gotuzzo E. Treatment failure in intestinal strongyloidiasis: An indicator of HTLV-I infection. Int J Infect Dis 2002;6:28-30.

6. Jeyamani R, Joseph AJ, Chacko A. Severe and treatment resistant strongyloidiasis - Indicator of HTLV-I infection. Trop Gastroenterol 2007;28:176-7.

7. Jaffe EF, Lejtenyi MC, Noya FJ, Mazer BD. Secondary hypogammaglobulinemia. Immunol Allergy Clin North Am 2001;21:141-63.

8. Brandt de Oliveira R, Voltarelli JC, Meneghelli UG. Severe strongyloidiasis associated with hypogammaglobulinaemia. Parasite Immunol 1981;3:165-9.

9. Seet RC, Lau LG, Tambyah PA. Strongyloides hyperinfection and hypogammaglobulinemia. Clin Diagn Lab Immunol 2005;12:680-2.

10. Mansfield LS, Schad GA. Strongyloides stercoralis infection in IgA-deficient dogs. Am J Trop Med Hyg 1992;47:830-6. 